\title{
VAŽNOST STATISTIČKE PISMENOSTI U MODERNOM OKRUŽENJU
}

\section{THE IMPORTANCE OF STATISTICAL LITERACY IN MODERN ENVIRONMENT}

SAŽETAK: Statistička pismenost postala je neophodan dio privatnog i poslovnog života. Nemogućnost ispravnog razumijevanja statističkih rezultata utječe na donošenje pogrešnih stavova i zaključaka. Navedene pogreške posebno dolaze do izražaja u poslovnom okruženju gdje se zbog pogrešnih zaključaka donose pogrešne odluke, a koje onda rezultiraju manjim rezultatima poslovanja. Stoga se u ovom stručnom radu prije svega ističe važnost razumijevanja pojma statističke pismenosti. Nakon toga izvode se zaključci o važnosti statističke pismenosti te se razmatraju njezine potencijalne koristi. Naposljetku, razmatra se trenutačna situacija u Hrvatskoj glede statističke pismenosti razmatrajući rad i položaj statistike u institucijama koje su odgovorne za postizanje određene razine statističke pismenosti.

KLJUČNE RIJEČI: primjena statističkih metoda, statistička pismenost, statistički način razmišljanja.

JEL: C00, O10.

ABSTRACT: Statistical literacy has become an essential part of private and business life. The inability to properly understand statistical results in the adoption of incorrect attitudes and conclusions. The mentioned errors are particularly pronounced in the business environment where erroneous conclusions lead to wrong decisions, which then result in lower business results. Therefore, in this professional paper, the emphasis is on the importance of understanding the statistical literacy concept. After that, conclusions on the importance of statistical literacy are drawn and consideration is given to its potential benefits. Finally, the current situation in Croatia regarding to statistical literacy is considered by observing work and position of statistics in the institutions responsible for achieving a certain level of statistical literacy.

KEY WORDS: statistical literacy, statistical methods use, statistical thinking.

JEL: C00, O10.

Doc. dr. sc. Berislav Žmuk, Sveučilište u Zagrebu, Ekonomski fakultet, Trg J. F. Kennedyja 6, HR-10000 Zagreb, Hrvatska, bzmuk@efzg.hr. 


\section{UVOD}

Sama riječ „statistika“ prema jednom stajalištu ima podrijetlo u latinskoj riječi status, u prijevodu stanje ili država (ovisno o razdoblju razvoja latinskoga jezika), dok prema drugom stajalištu ,statistika“ dolazi od talijanskih riječi stato (država) odnosno statista (osoba zadužena za državne poslove) (Sheynin, 2011.). Sukladno različitim definicijama podrijetla riječi „statistika“ te različitim definicijama samog pojma statistike (usporedi npr. Fisher, 1925.; Cangelosi, Taylor, Rice, 1979.; Šolak, 1990.; Freund, Wilson, 2003.; Ross, 2010.) položaj i uloga statistike se u društvu također mijenjala.

Mada se statistika kao pojam i u primjeni pojavljuje još davno prije, početkom razvoja suvremene statistike može se smatrati pojava rada u kojem je napravljena cjelovita statistička analiza zajedno o odgovarajućom diskusijom i donesenim zaključcima (Rothman, 1996.). Od pojave tog rada, 1662. godine pa sve do otprilike kraja 19. stoljeća, intenzivno se uglavnom radi samo na razvoju teorijske podloge dok se praktična primjena statistike zapostavlja. Ipak, zahvaljujući tehnološkom i društvenom razvoju (masovna proizvodnja, konkurencija, zahtjevi kupaca za kvalitetom proizvoda i usluga), početkom 20. stoljeća se primijetilo da bi poduzeća, ali i društvo u cjelini, mogla profitirati ako počnu primjenjivati statističke metode u svojem poslovanju. Ipak, postojeće statističke metode nisu bile primjerene za rješavanje problema koja su imala poduzeća. Stoga je došlo do svojevrsne podjele statistike na teorijsku te na primijenjenu statistiku. Dok je teorijska statistika nastavljala razvijati statističku podlogu, primijenjena statistika je krenula prilagođavati i razvijati nove statističke metode sukladno potrebama poduzeća (Mast, Does, 2006.). Nažalost, općenita razina prihvaćenosti statistike u poduzećima je bila na niskoj razini sve do pojave modernih računalnih rješenja koja su značajno povećala dostupnost samih računala te olakšala njihovo korištenje. Tako se od početka 80-ih godina 20. stoljeća počela lagano intenzivirati primjena statističkih metoda u poslovanju poduzeća (Van Matre, Gilbreath, 1987.). Usprkos potencijalnim koristima primjene statističkih metoda, još uvijek postoji velika averzija i negativan stav poduzeća prema njima, a što se posebice primjećuje u hrvatskim poduzećima (Žmuk, 2018.).

Određeno izbjegavanje statistike općenito, kao i kod poduzeća, primjećuje se i kod opće populacije. Navedeno se smatra velikim problemom jer stanovništvo ne razumije osnovne pokazatelje koji su im dostupni. Dapače, s razvojem tehnologije prikuplja se sve više podataka koji se onda, na određeni način i u određenom obliku, prezentiraju javnosti. Ključno za razumijevanje tih informacija jest posjedovanje određene razine statističke pismenosti te shvaćanje statističkog načina razmišljanja. Stoga je cilj ovog stručnog rada definirati pojmove statističke pismenosti, istaknuti njezinu važnost u modernom okruženju te razmotriti načine i mogućnosti unapređenja razine statističke pismenosti u općoj populaciji te u poduzećima.

Rad je organiziran kako slijedi. Nakon uvodnog dijela, u drugom dijelu rada se pristupa definiranju pojma statističke pismenosti. U trećem dijelu rada ističe se važnost posjedovanja statističke pismenosti u modernom okruženju. U četvrtom dijelu rada navode se mogućnosti povećanja opće razine statističke pismenosti s posebnim osvrtom na mjesta koja bi trebalo dodatno poboljšati kako bi se razina statističke pismenosti što prije i što kvalitetnije podigla na zadovoljavajuću razinu. Peti dio sadrži zaključna razmatranja te preporuke za buduća istraživanja. 


\section{POJMOVNO ODREĐIVANJE STATISTIČKE PISMENOSTI}

Prema Ferligoj (2015.), postoje mnoge različite definicije pojma statističke pismenosti, ali sve one proizlaze iz definicije Wallman (1993.) prema kojoj statistička pismenost je sposobnost razumijevanja i kritičkog procjenjivanja statističkih rezultata iz svakodnevnog života. Dodatno Wallman (1993.) ističe važnost vrednovanja statističkog načina razmišljanja u procesu donošenja u privatnom, ali i u poslovnom svijetu.

Watson (1997.) nadograđuje pojam statističke pismenosti te ga razdvaja na tri razine. Na prvoj razini statističke pismenosti navodi se osnovno razumijevanje statističke službene terminologije. Druga razina uključuje detaljnije poznavanje statističkog jezika te razumijevanje pojmova kod provedenih pojedinačnih istraživanja. Na trećoj razini osoba ima statistička znanja temeljem kojih može ocijeniti je li provedena odgovarajuća statistička analiza ili ne. Slično, Rumsey (2002.) razlikuje statističku kompetentnost ili „statističko državljanstvo“ od sposobnosti provođenja statističkog istraživanja.

Gal (2002.) ističe da je potrebno statističku pismenost promatrati samo kod odraslih osoba koja se više ne obrazuju i to prema dvije povezane komponente. Kod prve komponente promatra se sposobnost osoba tumačenja i kritičkog vrednovanja statističkih podataka s kojima se mogu svakodnevno susresti. Drugom komponentom obuhvaćena je sposobnost osoba raspravljanja i komuniciranja vlastitih reakcija na dobivene statističke informacije te donošenje valjanih zaključaka za poduzimanje odgovarajućih akcija.

U radovima novijeg datuma, definicije statističke pismenosti se pokušavaju pojednostaviti. Tako, prema Mittag (2010.), statistička pismenost se definira kao: kritičko razmišljanje o brojevima i korištenim statističkim metodama; sposobnost čitanja i tumačenja brojeva u izjavama, anketama, tablicama i grafikonima; sposobnost shvaćanja načina na koji se statističke asocijacije koriste kao dokaz uzročnih veza. Slično, Unece (2012.) promatra statističku pismenost kao sposobnost čitanja i tumačenja statističkih podataka prikazanih u različitim oblicima (grafikoni, tablice, izjave, ankete, studije) u različitim medijima (novine, internet, televizija).

Statističku pismenost potrebno je promatrati kao kontinuirani proces u kojemu se prepoznaje kako, kada i zašto se primjenjuju određene statističke metode (Chase, Yan, 2017.). Pri tome se na statističku pismenost ne smije promatrati samo kao učenje statističkih metoda, nego je potrebno znati i kako se te statističke metode ispravno koriste te kvalitetno znati protumačiti dobivene rezultate (Mallows, 1998.). Sukladno tome, Wild i Pfannkuch (1999.) smatraju da se statistički način razmišljanja te statistička pismenost temelji na sljedećem: prepoznavanju potrebe za podacima; transnumeraciji (engl. transnumeration - način prikupljanja podataka kod kojeg se obuhvaćaju važni elementi promatranog stvarnog procesa); varijaciji podataka; posebnom nizu različitih modela; kontekstnom znanju, statističkom znanju i sintezi. S druge strane, Ben-Zvi i Garfield (2004.) smatraju da statistička pismenost osigurava temelje za statistički način razmišljanja. Dodatno, prema njima, statistička pismenost uključuje razumijevanje samo osnovnog statističkog jezika i statističkih metoda dok statistički način razmišljanja sve to podiže na višu i složeniju razinu. Dakle, statistička pismenost i statistički način razmišljanja su usko povezani.

Definicija i pogled na statističku pismenost se mijenjao sukladno tome kako je i rasla svijest o važnosti statističke pismenosti u svakodnevnom poslovnom i privatnom okruženju. Očekuju se daljnja unapređenja definicije statističke pismenosti jer se, zasada, još 
uvijek zanemaruje problematika preciznog mjerenja i kvantifikacije statističke pismenosti u društvu.

\section{VAŽNOST I POLOŽAJ STATISTIČKE PISMENOSTI U MODERNOM OKRUŽENJU}

Važnost primjene statističkih metoda, pogotovo u poslovanju poduzeća, prepoznata je još početkom 20. stoljeća. Tako Herbert G. Wells prognozira da će jednog dana stanovnicima statistički načina razmišljanja, a time i statistička pismenost, postati neophodan poput sposobnosti čitanja i pisanja (Wilks, 1951.). Harry i Schroeder (2000.), naglašavajući ulogu statističke pismenosti u tehnološkom dobu, duboko su uvjereni da budućnost poduzeća uvelike ovisi o kvalitetnom razumijevanju statistike. Stoga Abraham (2007.) zaključuje da bi poduzeća statistički način razmišljanja i različite statističke metode trebala primjenjivati u svim svojim odjelima u svakodnevnom radu. Međutim, upravo Abraham (2007.) tu primjećuje jedan od problema vezanih uz statističku pismenost i statistički način razmišljanja, a to je neadekvatna i rijetka primjena statističkog pristupa u poslovanju poduzeća.

Postojeća istraživanja na uzorcima poduzeća diljem svijeta (vidjeti npr. Sanders, Mandrodt, 1994.; Deleryd, Garvare, Klefsjö, 1999.; Hargreaves, 2002.; Bergquist, Albing, 2006.) su pokazala da je u većini slučajeva razina primjena statističkih metoda u poduzećima vrlo niska. Dodatno, pokazalo se da, kad se i primjenjuju statističke metode u poduzećima, se primjenjuju samo one najjednostavnije. Sukladno tome, logično se nameće zaključak kako je razina statističke pismenosti i raširenost statističkog načina razmišljanja vrlo mala u poduzećima.

Nažalost, niti hrvatska poduzeća nisu iznimka po tom pitanju. Tako i istraživanja na uzorcima hrvatskih poduzeća (Žmuk, 2018.) pokazuju nedovoljnu razinu primjenu statističkih metoda te nisku razinu osviještenosti o važnosti statističke pismenosti i statističkog načina razmišljanja. Najrecentnije istraživanje (Žmuk, 2018.) pokazuje kako samo oko polovine hrvatskih poduzeća (51 \%) koristi statističke metode. Međutim, značajan udio poduzeća koja primjenjuju statističke metode koriste samo najosnovnije statističke metode te i njih primjenjuju rjeđe od jednom mjesečno (Žmuk, 2015.). Što se tiče ocjene razine vlastitog poznavanja i primjene statističkih metoda, poduzeća su sebi odnosno svojim djelatnicima u velikoj većini slučajeva dali ocjenu dobar (3) ili niže od toga. Usprkos tome, samo manji broj poduzeća ulaže u dodatno obrazovanje zaposlenih iz područja primjene statističkih metoda (Žmuk, 2015.).

Najveći i najznačajniji problem koji ograničava postizanje više razine statističke pismenosti je upravo nedovoljna razina obrazovanja iz navedenoga područja. Obrazovanje iz područja statističke pismenosti je nužno jer sama primjena statističkih metoda nije jamac da će osoba moći dobivene podatke pretvoriti u izvor korisnih informacija (Bayle, 2001.). Zbog lake dostupnosti pristupačnih i jednostavnih za korištenje statističkih programa, svatko može ubaciti podatke u neki od statističkih programa, odabrati primjenu određene statističke metode i doći do rezultata obrade. Međutim, upitno je koristi li ta osoba pouzdani statistički program koji se redovito ažurira sukladno razvoju statističkih metoda. Također, pitanje je, je li osoba odabrala primjenu odgovarajuće statističke metode te je li ispravno definirala sve parametre te metode. Naposljetku, sposobnost osobe da razumije dobivene 
rezultate, da ih smisleno protumači i temeljem njih donese ispravne zaključke je ključni korak u procesu primjene statističkih metoda (kao što to i sugerira Bayle, 2001.). Shodno tome, obrazovanje iz područja statističke pismenosti ne bi trebalo naglasak stavljati samo na primjenu statističkih metoda odnosno na to kako se određeni pokazatelji i mjere izračunavaju, već bi trebalo u potpunosti kvalitetno pokriti cjelokupni proces primjene statističkih metoda i to od početne faze prikupljanja podataka pa sve do tumačenja dobivenih rezultata i donošenja valjanih zaključaka.

Budući da imaju posebno važnu ulogu u cjelokupnom obrazovanju cijele zemlje, smatra se da su upravo sveučilišta te institucije koje bi trebale biti nositelji i pokretači razvoja statističke pismenosti (Abraham, 2007.). Ipak, Box (2000.) ukazuje na zastarjeli način podučavanja na statističkim kolegijima na kojima je naglasak na poznavanju svih detalja izračuna kod svake pojedine statističke metode. Box (2000.) smatra da uslijed razvoja računalne tehnologije više nije potrebno toliko ići u same izračune, već da se mora inzistirati na razvoju statističkog načina razmišljanja. Međutim, mada se slaže da je uloga sveučilišta vrlo važna u podizanju razine statističke pismenosti, Cobanovic (2002.) ističe dva čimbenika koja značajno sprječavaju podizanje razine statističke pismenosti: nedostatak sredstava za nabavu odgovarajuće računalne infrastrukture te nezainteresiranost i stanovita odbojnost studenata općenito prema statistici i statističkim kolegijima. Ipak, u određenim sredinama, poput Sjedinjenih Američkih Država, primjećuje se porast broja studenata koji upisuju statističke kolegije (Lutzer, Maxwell, Rodi, 2002.; Conference Board of Mathematical Sciences, 2010.). Navedeno se može smatrati pozitivnim pomakom jer Mittag (2010.) upozorava da nedostatak kompetentnosti iz područja statistike i statističke pismenosti predstavlja rizik za mlade ljude koji bi zbog toga mogli završiti na lošijim radnim mjestima. Cobb (1993.) dodatno ističe svoju zabrinutost glede sposobnosti i stručnosti nastavnika koji predaju na statističkim kolegijima. Time Cobb (1993.) zapravo poziva na dodatni oprez jer pogrešnim učenjem razina kvalitete statističke pismenosti se, ustvari, može i smanjiti.

Dok je statistička pismenost općoj populaciji prije svega potrebna za informiranje o određenim pojavama koje su od općeg interesa, statistička pismenost u poduzećima ima dodatnu ulogu savjetnika u procesu donošenja poslovnih odluka. Dapače, Montgomery (2000.) ističe da je statistička pismenost ključna za svako poduzeće te da bi poduzeća svakako trebala primjenjivati statističke metode. Dakako, postoje i određene prepreke zbog kojih statistička pismenost nije na visokoj razini u poduzeća te zbog kojih se statističke metode rijetko primjenjuju. Tako, Makrymichalos et al. (2005.) kao glavne prepreke vide u averziji i otporu zaposlenih prema statistici, preniskoj razini statističke pismenosti i statističkog obrazovanja u poduzeću te nesposobnosti menadžera koji se boje koristiti statističke metode.

Položaj i tretman statističke pismenosti i primjene statističkih metoda, ponajprije u poduzećima, bio bi zasigurno puno bolji kad bi bile prepoznate njihove mogućnosti i potencijalne koristi. Osim kvalitetnijeg praćenja određenih pojava, statistička pismenost i primjena statističkih metoda može rezultirati boljim rezultatima poslovanja. Tako Rao (2001.), na temelju empirijskih rezultata iz poslovne prakse, daje primjere prema kojima su poduzeća, koja su odlučila početi primjenjivati statističke metode, uspjela povećati vlastitu proizvodnju za čak do $100 \%$ bez ikakvih dodatnih posebnih ulaganja (osim onih vezanih uz primjenu statističkih metoda). Premda se iznosi potencijalnih koristi za poduzeća zbog podizanja razina statističke pismenosti i primjene statističkih metoda razlikuju među po- 
duzećima, pokazalo se da je vrijednost tih dodatnih koristi uglavnom veća od troškova vezanih za ulaganje u statističku pismenost i primjenu statističkih metoda (Žmuk, 2015.).

\section{MOGUĆNOSTI UNAPREĐENJA POSTOJEĆE RAZINE STATISTIČKE PISMENOSTI}

Proces povećanja razine statističke pismenosti nije jednostavan niti kratkotrajan. Kako bi taj proces uspio i polučio odgovarajuće rezultate, nužna je intenzivna suradnja između institucija i profesionalnih udruga kojima je zajednički cilj upravo podizanje razine statističke pismenosti, promicanje kulture primjene statističkih metoda i podizanje svijesti o potencijalnim koristima statistike općenito. Sukladno tome, na području unapređenja razine statističke pismenosti potrebno je osigurati suradnju između Državnog zavoda za statistiku, svih sveučilišta u Hrvatskoj te Hrvatskog statističkog društva.

Prema Državnom zavodu za statistiku (2019.a), ta institucija je glavni nositelj, diseminator i koordinator sustava službene statistike Republike Hrvatske. Sukladno tome Državni zavod za statistiku ima iznimno važnu ulogu u podizanju i isticanju važnosti statističke pismenosti u javnosti. Povećanjem razine statističke pismenosti unapređuje se ne samo značaj statističkih informacija u društvu nego se i izgrađuje važnost i legitimnost nositelja službene statistike (Helenius, 2010.).

Prema Ferligoj (2015.) postoje nekoliko izravnih načina putem kojih Državni zavod za statistiku može utjecati na razinu statističke pismenosti. Prvi način jest objavom sažetih i lako shvatljivih statističkih informacija na odgovarajućim mjestima poput mrežnih stranica Državnog zavoda za statistiku, statističkih strukovnih udruženja i obrazovnih institucija koje održavaju nastavu iz područja statistike. Dakako, osim na mrežnim stranicama, te informacije se mogu javno objaviti na televiziji, radiju, dnevnom tisku i slično. Isto tako, bilo bi poželjno da se, osim gotovih rezultata obrade, u tim objavama nalaze dodatne informacije o korištenoj metodologiji istraživanja te primijenjenim statističkim metodama. Sljedeći izravni način utjecaja Državnog zavoda za statistiku na razinu statističke pismenosti se ogleda u stratificiranom pristupu općoj populaciji te savjetovanju o ispravnom korištenju i tumačenju danih statističkih rezultata. Tako bi Državni zavod za statistiku mogao održavati različite seminare za korisnike statističkih podataka koji oni proizvode kako bi korisnici bolje razumjeli dobivene podatke. Isto tako, posebno je bitno javnost upozoravati na karakteristične zlouporabe statističkih rezultata, a koji proizlaze iz nerazumijevanja statističkog pristupa i statističkog načina razmišljanja.

Premda Državni zavod za statistiku javno objavljuje cijeli niz različitih statističkih publikacija i nizova podataka, problem je što ti statistički podaci nisu dovoljno dobro stratificirani prema kategorijama korisnika (Poljičak Sušec, Jerak Muravec, Stančić, 2014.). Stoga bi Državni zavod za statistiku trebao više poraditi na tom segmentu, ali i na unapređenju vlastitih mrežnih stranica. Naime, osim što se koristi zastarjeli dizajn mrežnih stranica, određenim podacima je jako teško pristupiti. Pod teškim pristupanjem smatra se da je određene varijable teško pronaći jer se one nalaze u dokumentu koji nije prijateljski nastrojen prema korisniku. Tako, između ostaloga, korisnik mora ručno prepisivati podatke iz publikacija dostupnih na mrežnim stranicama. Dodatni je problem što se u publikacijama nalazi samo ograničen broj vrijednosti određene varijable (npr. podaci samo za dvije godi- 
ne) te u tom slučaju korisnik mora tražiti starije publikacije. Navedeni problemi bi se riješili uspostavom sustava u kojemu korisnik lako pretražuje varijable te ujedno sam definira određene parametre pretraživanja (poput primjerice, razdoblja promatranja). Naposljetku, opcija preuzimanja podataka u određenim datotečnim oblicima spremnih za obradu u statističkim programima je nešto što bi Državni zavod za statistiku svakako trebao uključiti u svojim bazama podataka.

Sam rad Državnog zavoda za statistiku uvelike ovisi o dodijeljenim mu proračunskim sredstvima. Usprkos tome, Državni zavod za statistiku je 2017. godine, zajedno s Eurostatom i ostalim europskim nacionalnim statističkim uredima, krenuo u projekt Europskoga statističkog natjecanja, poznatijeg pod nazivom Statistička olimpijada (Državni zavod za statistiku, 2019.b). Statistička olimpijada je izvrstan primjer podizanja razine statističke pismenosti među mlađom populacijom. Naime, na ovom natjecanju mogu sudjelovati samo srednjoškolci, okupljeni u timove, zajedno sa svojim mentorima.

Državni zavod za statistiku imao je i presudnu ulogu u osnivanju statističke strukovne udruge Hrvatsko statističko društvo, koje je kao takvo jedinstveno u Hrvatskoj (Hrvatsko statističko društvo, 2019.a). Hrvatsko statističko društvo je osnovano 2005. godine, ali je s pravim aktivnim radom počelo tek 2015. godine (Hrvatsko statističko društvo, 2019.a). Jedan od prvih koraka je bilo pokretanje znanstvenog časopisa „Croatian Review of Economic, Business and Social Statistics", kojim se nastoji potaknuti primjena različitih statističkih metoda u različitim znanstvenim područjima (Hrvatsko statističko društvo, 2019.b). Hrvatsko statističko društvo je također uspješno organiziralo dvije međunarodne znanstvene konferencije koje su se održale 2016. godine u Zagrebu te 2018. godine u Opatiji (Hrvatsko statističko društvo, 2019.a). U okviru Hrvatskog statističkog društva djeluje i nekoliko sekcija od kojih je potrebno posebno istaknuti sekciju „Žene u statistici“ kojoj je jedan od ciljeva upravo „poboljšanje obrazovanja i statističke pismenosti za statističarke“ (Hrvatsko statističko društvo, 2019.c). Hrvatsko statističko društvo sastoji se od preko 100 članova od čega značajan udio imaju zaposlenici Državnog zavoda za statistiku te nastavnici Sveučilišta u Zagrebu (Hrvatsko statističko društvo, 2019.a).

Sveučilišni nastavnici imaju važnu ulogu u promicanju i unapređivanju statističke pismenosti ne samo kod postojećih studenata, nego i kod njihovog privatnog i poslovnog okruženja. Također, sveučilišni nastavnici imaju obvezu odgajati sljedeće generacije nastavnika koji neće prenositi svoja stečena znanja samo studentima na sveučilišnim programima, nego i učenicima u osnovnim i srednjim školama. Nažalost, premda bi se nastava iz statistike trebala održavati na svim razinama obrazovanja, postoje određene europske zemlje koje nemaju razvijen niti jedan sveučilišni program namijenjen primjeni statističkih metoda (Ferligoj, 2015.). Dok, primjerice, Slovenija na sveučilišnoj razini ima samo doktorski studij iz područja statistike (Univerza v Ljubljani, 2019.), Hrvatska ima sveučilišni specijalistički studij (Ekonomski fakultet - Zagreb, 2019.). Na nižim razinama obrazovanja situacija je još ozbiljnija. Tako primjerice, strukovni kurikul za stjecanje kvalifikacije ekonomist, predviđa samo jedan nastavni predmet iz statistike i to u trećem razredu u trajanju od dva sata tjedno (Narodne novine, 2017.). Doduše, određene statističke metode jesu zastupljene u okviru nastave iz matematike, ali u nedovoljnoj mjeri te se tamo ne potiče razvoj statističkog načina razmišljanja.

Sukladno tome, u obrazovni sustav trebalo bi uvrstiti više nastave iz područja statistike. Dakako, nastavu je potrebno prilagoditi uzrastu učenika te prethodnome znanju. Smith 
(1998.) smatra da bi učenici i studenti trebali učiti statistiku na način da sudjeluju aktivno u procesu prikupljanja podataka te da uče primjenom statističkih metoda, pisanjem izvještaja te prezentacijom dobivenih rezultata. Na taj način razina statističke pismenosti će kvalitetno rasti, a što će imati mnogobrojne pozitivne učinke na društvo u cjelini.

\section{ZAKLJUČAK}

Usprkos svim potencijalnim koristima koje primjena statističkih metoda i statistička pismenost može donijeti poduzećima te društvu u cjelini, statistika je kao takva još uvijek nepravedno zapostavljena. Prvi i glavni problem jest u postojanju određene averzije i straha prema statistici. Nedovoljno poznavanje potencijala statistike dovodi do odbijanja svega što ima veze sa statistikom. Tako se statistički podaci, koje objavljuje na primjer Državni zavod za statistiku, smatraju lažnima ili pogrešnima. Zbog nerazumijevanja i nepostojanja kulture statističke pismenosti, objavljeni službeni rezultati se ismijavaju ili se pogrešno tumače. Državni zavod za statistiku i Hrvatsko statističko društvo su na dobrom tragu izgradnje i podizanja razine statističke pismenosti u Hrvatskoj, ali u tome će im svakako dobro doći dodatna pomoć od strane cijelog obrazovnog sustava. Potrebno je imati u vidu izreku da „statistika ne laže, lažu oni koji je ne razumiju“.

Glavnim ograničenjem rada može smatrati činjenica da stvarna razina statističke pismenosti u Hrvatskoj nije precizno izmjerena. U radu se polazi od pretpostavke, jer na to ukazuju postojeća istraživanja koja su provedena na specifičnim dijelovima populacije, da je razina statističke pismenosti vrlo niska. Stoga bi u budućim istraživanjima trebalo pristupiti osmišljavanju i provođenju sveobuhvatnog istraživanja o razini statističke pismenosti u Hrvatskoj. Pri tome bi trebalo svakako opću populaciju stratificirati prema starosti. Sukladno dobivenim rezultatima tog istraživanja bit će potrebno poduzeti određene akcije unapređenja razine statističke pismenosti populacije.

\section{LITERATURA}

1. Abraham, B. (2007), Implementation of Statistics in Business and Industry, Revista Colombiana de Estadística, Vol. 30, No. 1, pp. 1-11.

2. Bayle, P. (2001), Illustration of six sigma assistance on a design project, Quality Engineering, Vol. 13, No. 3, pp. 341-348.

3. Ben-Zvi, D., Garfield, J. (2004), Statistical literacy, reasoning, and thinking: Goals, definitions, and challenges. U: Ben-Zvi, D., Garfield, J. (Eds.), The Challenge of Developing Statistical Literacy, Reasoning and Thinking, pp. 3-15, Boston: Kluwer.

4. Bergquist, B., Albing, M. (2006), Statistical methods: Does anyone really use them?, Total Quality Management \& Business Excellence, Vol. 17, No. 8, pp. 961-972.

5. Box, G. E. P. (2000), Statistic for discovery, The Center for Quality and Productivity Improvement, Report No. 179, Madison: University of Wisconsin.

6. Cangelosi, V. E., Taylor, P. H., Rice, P. F. (1979), Basic Statistics: A Real World Approach, 2. izd., St. Paul: West Publishing Company. 
7. Chase, J. P., Yan, Z. (2017), Assessing and Measuring Statistics Cognition in Higher Education Online Environments: Emerging Research and Opportunities: Emerging Research and Opportunities, Hershey: IGI Global.

8. Cobanovic, K. (2002), Role of Statistics in the Education of Agricultural Science Students, U: Phillips, B. (Ed.), Proceedings of the Sixth International Conference on Teaching Statistics, Cape Town: International Statistical Institute.

9. Cobb, G. W. (1993), Reconsidering Statistics Education: A National Science Foundation Conference, Journal of Statistics Education, Vol. 1, No. 1, pp. 1-26.

10. Conference Board of Mathematical Sciences (2010), Chapter 1: Draft [online], dostupno na: http://www.ams.org/profession/data/cbms-survey/Chapter1DraftTables2.pdf (27. ožujka 2019.).

11. Deleryd, M., Garvare, R., Klefsjö, B. (1999), Experiences of Implementing Statistical Methods in Small Enterprises, Total Quality Management Magazine, Vol. 11, No. 5, pp. 341-350.

12. Državni zavod za statistiku (2019), O nama [online], dostupno na: https://www.dzs.hr/ Hrv/about_us/about_us.htm (27. ožujka 2019.).

13. Državni zavod za statistiku (2019), Europsko statističko natjecanje (ESC) [online], dostupno na: https://olimpijada.dzs.hr/ (27. ožujka 2019.).

14. Ekonomski fakultet - Zagreb (2019), Statističke metode za ekonomske analize i prognoziranje [online], dostupno na: http://www.efzg.unizg.hr/default.aspx?id=7075 (27. ožujka 2019.).

15. Ferligoj, A. (2015), How to Improve Statistical Literacy?, Metodološki zvezki, Vol. 12, No. 1, pp. 1-10.

16. Fisher, R. A. (1925), Statistical Methods for Research Workers, Edinburgh: Oliver \& Boyd.

17. Freund, R. J., Wilson, W. J. (2003), Statistical Methods, 2. izd., San Diego: Academic Press.

18. Gal, I. (2002), Adults's statistical literacy: Meanings, components, responsibilities. International Statistical Review, Vol. 70, No. 1, pp. 1-25.

19. Hargreaves, C. A. (2002), Do Managers Make Decisions Using Statistics?, Developing a Statistically Literate Society, The Sixth International Conference on Teaching Statistics, 7-12 srpanj, 2002., Cape Town, South Africa, [online], dostupno na: http:// www.stat.auckland.ac.nz/ iase/publications/1/10_22_ha.pdf [27. ožujka 2019.].

20. Harry, M., Schroeder, R. (2000), Six Sigma, the Breakthrough Management Strategy Revolutionizing the World's Top Corporations, New York: Doubleday.

21. Helenius, R. (2010), Improving statistical literacy by national and international cooperation [online], dostupno na: http://iase-web.org/documents/papers/icots8/ICOTS8_7H2_HELENIUS.pdf (27. ožujka 2019.).

22. Hrvatsko statističko društvo (2019a), About [online], dostupno na: http://www.hsdstat.hr/en/about/ (27. ožujka 2019.).

23. Hrvatsko statističko društvo (2019b), Croatian Review of Economic, Business and Social Statistics (CREBSS) [online], dostupno na: http://www.hsd-stat.hr/en/crebss_en/ (27. ožujka 2019.). 
24. Hrvatsko statističko društvo (2019c), Sekcija “Žene u statistici” [online], dostupno na: http://www.hsd-stat.hr/hr/zene-u-statistici/ (27. ožujka 2019.).

25. Lutzer, D. J., Maxwell, J. W., Rodi, S. B. (2002), Statistical Abstract of Undergraduate Programs in the Mathematical Sciences in the United States: Fall 2000 CBMS Survey, American Mathematical Society.

26. Makrymichalos, M., Antony, J., Antony, F., Kumar, M. (2005), Statistical Thinking and its Role for Industrial Engineers and Managers in the 21st Century, Managerial Auditing Journal, Vol. 20, No. 4, pp. 354-363.

27. Mallows, C. (1998). 1997 Fisher Memorial Lecture: The zeroth problem, American Statistician, Vol. 52, No. 1, pp. 1-9.

28. Mast, J., Does, R. J. M. M. (2006), Industrial statistics: a discipline with opportunities and challenges, Statistica Neerlandica, Vol. 60, No. 3, pp. 270-282.

29. Mittag, H.-J. (2010), Promoting statistical literacy: A European pilot project to bring official statistics into university and secondary school classrooms [online], dostupno na: http://www.fernuni-hagen.de/jmittag/publikationnen/ICOTS8-2010.pdf (27. ožujka 2019.).

30. Montgomery, D. C. (2000), The Future of Industrial Statistics, ORiON, Vol. 16, No. 1, pp. 1-22.

31. Narodne novine (2017), Odluka o uvođenju strukovnog kurikuluma za stjecanje kvalifikacije ekonomist (060724) u obrazovnom sektoru ekonomija, trgovina i poslovna administracija, 85/2017, Zagreb: Narodne novine.

32. Poljičak Sušec, M., Jerak Muravec, N., Stančić, H. (2014), Statistical Literacy as an Aspect of Media Literacy, Medijska istraživanja/Media Research, Vol. 20, No. 2, pp. 131-155.

33. Rao, C. R. (2001), Statistics: Reflections on the Past and Visions for the Future, Communications in Statistics - Theory and Methods, Vol. 30, No. 11, pp. 2235-2257.

34. Ross, S. M., (2010), Introductory Statistics, 3. izd., San Diego: Elsevier.

35. Rothman, K. J., (1996), Lessons from John Graunt, The Lancet, Vol. 347, No. 8993, pp. 37-39.

36. Rumsey, D. J. (2002), Statistical Literacy as a Goal for Introductroy Statistics Courses, Journal of Statistics Education, Vol. 10, No. 3, pp. 1-8.

37. Sanders, N. R., Manrodt, K. B. (1994), Forecasting Practices in US Corporations: Survey Results, Interfaces, Vol. 24, No. 2, pp. 92-100.

38. Sheynin, O. (2011), Statistics, History of, u: Lovric, M., ed., International Encyclopedia of Statistical Science, Vol. 3, Berlin: Springer.

39. Smith, G. (1998), Learning Statistics by Doing Statistics, Journal of Statistics Education, Vol. 6, No. 3, pp. 1-12.

40. Šolak, Nj. B. (1990), Statistika za poslovno odlučivanje, Beograd: Naučna knjiga.

41. Unece (2012), Making Data Meaningful, A guide to improving statistical literacy [online], dostupno na: https://www.unece.org/fileadmin/DAM/stats/publications/2013/ Making_Data_Meaningful_4.pdf (27. ožujka 2019.). 
42. Univerza v Ljubljani (2019), Interdisciplinarni doktorski študijski program statistika [online], dostupno na: https://www.uni-lj.si/studij/doktorski/statistika/ (27. ožujka 2019.).

43. Van Matre, J. G., Gilbreath, G. H. (1987), Statistics for Business and Economics, 3. izd., Homewood: Business Publications.

44. Wallman, K. K. (1993), Enhancing Statistical Literacy: Enriching Our Society, Journal of the American Statistical Association, Vol. 88, No. 42, pp. 1-8.

45. Watson, J. (1997). Assessing statistical literacy through the use of media surveys. U: Gal, I., Garfield, J. (Eds.), The assessment challenge in statistics education (pp. 107121). Amsterdam, The Netherlands: International Statistical Institute/IOS Press.

46. Wild, C. J., Pfannkuch, M. (1999), Statistical Thinking in Empirical Enquiry, International Statistical Review, Vol. 67, No. 3, pp. 223-265.

47. Wilks, S. S. (1951), Undergraduate statistical education, Journal of the American Statistical Association, Vol. 46, No. 253, pp. 1-18.

48. Žmuk, B. (2015), Business Sample Survey Measurement on Statistical Thinking and Methods Adoption: the Case of Croatian Small Enterprises, Interdisciplinary description of complex systems, Vol. 13, No. 1, pp. 154-166.

49. Žmuk, B. (2018), Primjena statističkih metoda i poslovni rezultati poduzeća u Hrvatskoj: neiskorišteni potencijal, Zbornik Ekonomskog fakulteta u Zagrebu, Vol. 16, No. 1, pp. 21-41. 